\title{
Constructing a Fuzzy Model to Predict Math Anxiety
}

\author{
Hari Purnomo Susanto ${ }^{1,2^{*}}$, Mega Isvandiana Purnamasari ${ }^{1}$ \\ ${ }^{I}$ Educational Evaluation and Research, Universitas Negeri Yogyakarta, Yogyakarta, Indonesia \\ ${ }^{2}$ STKIP PGRI Pacitan, Jawa Timur, Indonesia \\ "Corresponding author.Email: haripurnomo.2021@student.uny.ac.id
}

\begin{abstract}
This study aims to construct a fuzzy model for predicting math anxiety by using mathematics self-efficacy and positive attitude towards mathematics as input variables. The model focuses on using fuzzy rules developed by Wang, but is limited to the third step, because the variables are related to human psychology. The data used were taken from senior high schools in Pacitan, East Java. One thousand data were used to build fuzzy rules and 26 data for testing the model. There are three models formed, namely two fuzzy models and one regression model. Model 1 and Model 2 are fuzzy models built using Wang's method until the third step and complete rules, respectively. The MAPE calculation shows that all of the models have good accuracy to predict math anxiety. The MSE shows that Model 1 is the best model among the three models. In addition, based on the standard deviation, Model 1 is the better at controlling uncertainty in the raw data than the regression model.
\end{abstract}

Keywords: Anxiety, attitude to word math, fuzzy model, mathematics, self-efficacy.

\section{INTRODUCTION}

Even still, the human psychological factor needs realistic powers of reasoning and interpretation to support a successful learning outcome. It is pertaining to anxiety, self-efficacy, and positive attitudes. Anxiety has a negative effect on mathematics learning achievement [1]-[5]. Furthermore, other psychological factors which affect learning and mathematics learning outcomes are self-efficacy [6], [7], and attitudes towards mathematics [5], [8]. Both factors have a mathematical anxiety correlation [9]. With reference to the aforementioned researches, self-efficacy has a negative correlation with math anxiety [9], [10]. The positive attitudes towards mathematics have a negative correlation with mathematics anxiety. Conversely, negative attitudes have a positive correlation with math anxiety [9].

Understandably, based on the correlation between anxiety with self-efficacy and attitude towards mathematics, this study is then purposefully conducted in order to uncover the predictions of anxiety which was carried out using self-efficacy and attitude data based on fuzzy systems. The reason for using the fuzzy systems in human behavior studies is to reduce the uncertainty of the obtained data from the use of the questionnaire [11].

The fuzzy concepts have been extensively applied to predict data, some of which are fuzzy applications to predict time series data on Indonesia inflation rate [12], earthquake [13], temperature [12], and in psychology [11], [14], [15]. The advantage of fuzzy systems for predictions is that it does not require parametric conditions to be met as in regression, it is suitable for data that do not contain trends, and it can be constructed without data. Researchers or experts experiences can be used to set the fuzzy rules system that will be formed.

A fuzzy system requires a fuzzy rule that is used to decide the output. Fuzzy rules are formed by selecting data pairs or based on expert statements. The rule selection method includes the Look-Up Scheme Table Method [16] and the Complete Fuzzy Rule Method, which is generalized from Wang's method [17]. Generating Fuzzy rules that are based on expert judgments can be done without any data to construct the fuzzy model [11].

Based on the information above, this study is focused on a fuzzy rule selection method proposed by selecting all possible outputs which appear in the same 
input pair. For instance, if there appear, in the process of forming fuzzy rules, input-output pairs as (A1, B2: C1), (A1, B2: C2) and (A1, B2: C3), and this can be obtained in the third step of Wang's method. If we use the full step of Wang's [16] selection rule, then just one rule is obtained, in order to avoid chaos in output. This method is used because the output must be able to represent each student's math anxiety.

\section{METHOD}

\subsection{Variable}

There are two independent variables, namely math self-efficacy $\left(x_{1}\right)$ and the positive attitude of students in mathematics $\left(x_{2}\right)$. Students' math anxiety $(y)$ is the dependent variable.

\subsection{Respondents}

The math anxiety, math self-efficacy, and positive attitudes data were taken from 1,026 high school students in Pacitan, East Java, Indonesia. As many as 1,000 data were used to form the model and 26 data were used to test it.

\subsection{Constructing Fuzzy System and Data Analysis}

The fuzzy rules were formed from input-output data pairs. The input variables were self-efficacy and positive attitude of students in mathematics; whereas, the output was math anxiety. Before forming the fuzzy rules, fuzzy sets had to be built based on the data range from each variable [16]. These fuzzy sets described the categories of each variable by using nine language term levels. The math anxiety and self-efficacy variables were written using language variable levels including very low, rather very low, low, rather low, moderate, rather high, high, slightly very high, very high. Then, the level for positive attitudes towards Math includes very negative, rather very negative, negative, rather negative, neutral, rather positive, positive, rather very positive, very positive. For more details see Figure 1 and Figure 2

The fuzzy model elements used are Singleton fuzzification, multiplication inference engine, central average defuzzification, and Gaussian membership function. The fuzzy-based rules are determined using two methods, namely, the Look Up Scheme Table [16] and the rule selection method proposed in this article. Furthermore, the fuzzy model optimization process is done by redefining the values range or support of each formed fuzzy set [17].

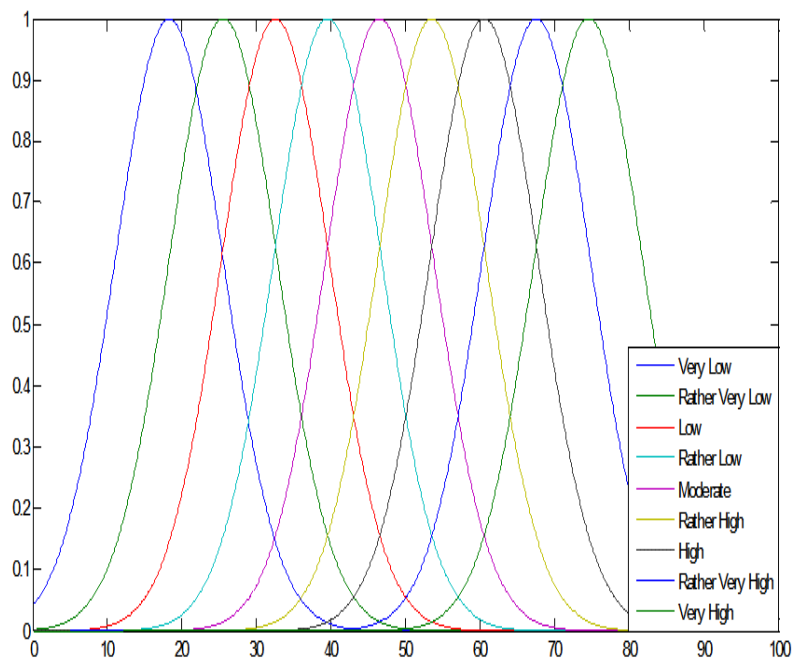

Figure 1 Fuzzy linguistic variable for math anxiety and self-efficacy

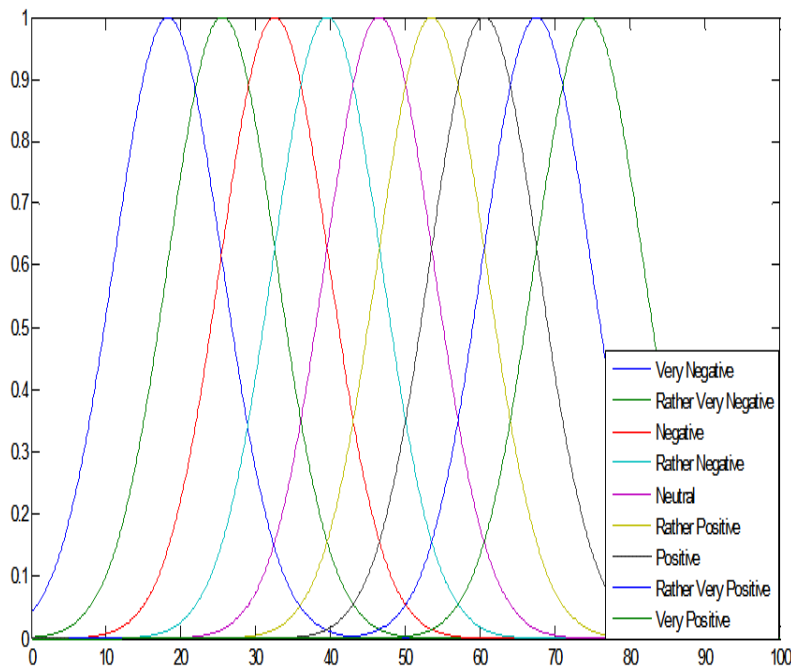

Figure 2 Fuzzy linguistic variables for students' attitude toward math

The process of the Table look-up scheme method [16] to build the fuzzy rules was carried out in the following steps.

Let $\mathrm{N}$ be given pairs of training data from selfefficacy data $\left(x_{1}\right)$, attitude $\left(x_{2}\right)$, and math anxiety $(y)$ : $\left(x_{1 \mathrm{i}}, x_{2 \mathrm{i}} ;{ }_{\mathrm{Yi}}\right)$ for $i=1,2, \ldots, n$

Step1. Define the universal set of input and output domains.

Step2. Define the fuzzy set on a continuum, normal and complete universal set.

Step3. Form one fuzzy rule for one pair of training data and obtain fuzzy rules:

$$
A_{\mathfrak{L}}^{\mathbb{I}} B_{\mathrm{i}}^{\llbracket} \rightarrow C_{\mathbb{i}}^{\llbracket}
$$


Step4. Calculate the degree of each fuzzy rule obtained from step 3. If there are conflicting fuzzy rules, then select the highest degree of fuzzy rules for each data pair.

$$
D(\text { rule })=\prod_{i=1}^{n} \mu_{A i}\left(x_{1 i}\right) \cdot \mu_{B_{i}}\left(x_{2 i}\right) \cdot \mu_{C_{i}}\left(y_{i}\right)
$$

Step5. Form fuzzy rules base obtained from step4.

Step6. The form of a fuzzy model consists of fuzzy rule bases, fuzzification, fuzzy inference engines, and defuzzification. To get the best model, a fuzzy model is constructed with singleton fuzzification, multiplication inference engine, central mean defuzzification, and Gaussian membership function, namely:

$$
y_{i}^{*}=f\left(x_{1 i}, x_{1 i}\right)=\frac{\sum_{j=1}^{m} y_{j}^{* l} \cdot \exp \left(-\left(\frac{\left(x_{1}-x_{1 j}^{* l}\right)^{2}}{m^{2}}+\frac{\left(x_{2}-x_{2 j}^{* l}\right)^{2}}{\sigma^{2}}\right)\right)}{\sum_{j=1}^{m} \exp \left(-\left(\frac{\left(x_{1}-x_{1}^{* l}\right)^{2}}{\sigma^{2}}+\frac{\left(x_{2}-x_{2}^{* l}\right)^{2}}{\sigma^{2}}\right)\right.}
$$

Note that:

$y_{i}^{8} y_{\tilde{l}}^{8} y_{i}^{8}=$ the $i$-th students' Math anxiety predictions value

$m=$ the number of formed fuzzy rules

$y_{j}^{8} y_{j}^{8 I}=$ the center of the fuzzy set $C$ output in the $j$-th rule

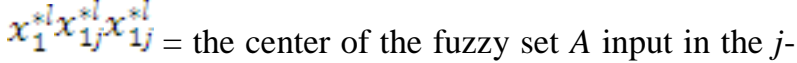
th rule

$x_{2}^{8 \mathrm{II}} x_{2 j}^{\mathrm{el}} x_{2 j}^{\mathrm{el}}=$ the center of the fuzzy set $B$ input in the $j$ th rule

$\sigma_{1} \sigma_{1}=$ the support for each $A$ fuzzy set

$\sigma_{2} \sigma_{2}=$ the support for each $B$ fuzzy set

Then, the fuzzy model formed was compared with the regression model using Mean Square Error (MSE) and Mean Absolute percentage error (MAPE).

$$
\begin{aligned}
& M S E=\frac{\sum_{i=1}^{n}\left(y_{i}-y_{i}^{*}\right)}{n} \\
& M A P E=\sum_{i=1}^{n}\left|\frac{y_{i}-y_{i}^{*}}{y_{i}}\right| \times 100 \%
\end{aligned}
$$

\section{RESULTS AND DISCUSSION}

The fuzzy models were constructed using nine fuzzy sets and its rule was generated using the Wang method. The following process of Wang's method [16] was obtained.

Step 1: the universal set of each variable for selfefficacy $\left(x_{1}\right)$, attitude $\left(x_{2}\right)$, and anxiety $(y),[1773]$, [17 75] and [15 73] respectively.
Step 2: the number of fuzzy sets used were adjusted to the number of language variable levels used in each variable.

Step 3: 124 fuzzy rules were successfully formed from each data pair called model 1 and obtained in Table 1 .

Step 4: Selecting rules to get optimal and effective rule from 124 were obtained to 35 rules, which were called model 2 .

Steps 5 and 6: A fuzzy model with conditions as shown in Table 1 was obtained. Furthermore, each model formed can be seen in the formulas below and Figures 3, 4, and 5.

\subsubsection{Fuzzy Model 1}

$$
y_{i}^{*}=f\left(x_{1 i}, x_{2 i}\right)=\frac{\sum_{j=1}^{35} y_{j}^{* l} \cdot \exp \left(-\left(\frac{\left(x_{1}-x_{1 j}^{* l}\right)^{2}}{13^{2}}+\frac{\left(x_{2}-x_{2 j}^{* l}\right)^{2}}{13^{2}}\right)\right)}{\sum_{j=1}^{35} \exp \left(-\left(\frac{\left(x_{1}-x_{1 j}^{* l}\right)^{2}}{13^{2}}+\frac{\left(x_{2}-x_{2 j}^{* l}\right)^{2}}{13^{2}}\right)\right)}
$$

\subsubsection{Fuzzy Model 2}

$$
y_{i}^{*}=f\left(x_{1 i}, x_{1 i}\right)=\frac{\sum_{j=1}^{124} y_{j}^{* l} \cdot \exp \left(-\left(\frac{\left(x_{1}-x_{1 j}^{* l}\right)^{2}}{6.9^{2}}+\frac{\left(x_{2}-x_{2 j}^{* l}\right)^{2}}{6.9^{2}}\right)\right)}{\sum_{j=1}^{124} \exp \left(-\left(\frac{\left(x_{1}-x_{1 j}^{* l}\right)^{2}}{6.9^{2}}+\frac{\left(x_{2}-x_{2 j}^{* l}\right)^{2}}{6.9^{2}}\right)\right)}
$$

\subsubsection{Regression Models}

$y *=66.55-0.43 x_{1}-0.05 x_{2}$

Table 1 The numbers of fuzzy sets and the rules of each model

\begin{tabular}{|l|l|l|l|}
\hline $\begin{array}{l}\text { Fuzzy } \\
\text { model }\end{array}$ & $\begin{array}{l}\text { Number of } \\
\text { fuzzy sets }\end{array}$ & $\begin{array}{l}\text { Rule selection } \\
\text { method }\end{array}$ & $\begin{array}{l}\text { Number } \\
\text { of rules }\end{array}$ \\
\hline $\begin{array}{l}\text { Model- } \\
1\end{array}$ & 9 fuzzy set & $\begin{array}{l}\text { The proposed } \\
\text { method }\end{array}$ & 124 rules \\
\hline $\begin{array}{l}\text { Model- } \\
2\end{array}$ & 9 fuzzy set & Wang's method & 35 rules \\
\hline
\end{tabular}

The model defined in Table 1 was then compared to the classical method of regression analysis. The prediction results of each model were compared by looking at the Mean Square Error (MSE), Mean Average Percentage Error (MAPE) [12], [17], [18], and its variance [11].

Table 2 shows the MSE and MAPE values of each fuzzy and regression model. Based on the value of the MSE, Model 1 is the best model when compared to other models, and Model 2 is not better than regression. Furthermore, the MAPE value shows that each model 
has a good level of accuracy in predicting math anxiety, this is indicated by the MAPE value which is between $10-20$ [19]. The standard deviation shows some uncertainty information of the data. The standard deviation described a variance in the data. The smaller standard deviation value showed the best model in controlling uncertainty [11]. In other words, the fuzzy model is better than the regression model, and Model 1 is the best model.

Table 2 MSE, MAPE and the Variance of Each Model for Trial data

\begin{tabular}{|l|l|l|l|}
\hline \multirow{2}{*}{ Model } & \multicolumn{2}{|l|}{ Trial data } \\
\cline { 2 - 4 } & MSE & MAPE & $\begin{array}{l}\text { Standard } \\
\text { deviation }\end{array}$ \\
\hline Model-1 & 51.468 & $13.93 \%$ & 2.74 \\
\hline Model-2 & 52.444 & $13.88 \%$ & 2.92 \\
\hline Regression & 52.151 & $14 \%$ & 3.26 \\
\hline
\end{tabular}

Table 3 MSE, MAPE and the Variance of Each Model for Test Data

\begin{tabular}{|l|l|l|l|}
\hline \multirow{2}{*}{ Model } & \multicolumn{2}{|l|}{ Testing data } \\
\cline { 2 - 4 } & MSE & MAPE & $\begin{array}{l}\text { Standard } \\
\text { deviation }\end{array}$ \\
\hline Model-1 & 44.188 & $14.13 \%$ & 2.27 \\
\hline Model-2 & 42.702 & $14.04 \%$ & 2.74 \\
\hline Regression & 48.993 & $15 \%$ & 2.88 \\
\hline
\end{tabular}

Table 3 shows that each model has good accuracy still, even though to predict test data and the standard deviation shows that Model 1 is the best model to predict the test data. To reinforce the results of this research, the prediction data were compared to the original data using the independence t-test, and the result is shown in Table 4.

Table 4 The average comparison between anxiety data prediction and original data with t-test

\begin{tabular}{|l|l|l|l|}
\hline & $\begin{array}{l}\text { Model } \\
1\end{array}$ & $\begin{array}{l}\text { Model } \\
2\end{array}$ & Regression \\
\hline t-value & 0.748 & 2.471 & 0.000 \\
\hline p-value & 0.455 & 0.014 & 1.000 \\
\hline
\end{tabular}

P-value $>0.05$ in Table 4 explains that model 1 and the regression model do not have an average difference when compared to the original data. These results reinforce that model 1 is better than Model 2.

Based on the aforementioned results, the fuzzy rules selection proposed is more suitable than the complete rules of Wang's [16] to be used to predict math anxiety.
This rule selection is the focuses of this study because the observed data relates to human psychology. As a result, many conditions may occur and cannot be avoided or eliminated, under Kushwaha \& Kumar [11] who build fuzzy rules where the same input conditions can have several different outputs. The difference is that the rules in this research are built and selected from empirical data, while Kushwaha \& Kumar [11] build the fuzzy rules based on expert judgment so that it does not require empirical data to build the fuzzy rules. Whereas, the Wang [16] method is based only on empirical data and ignores the conditions to human psychology.

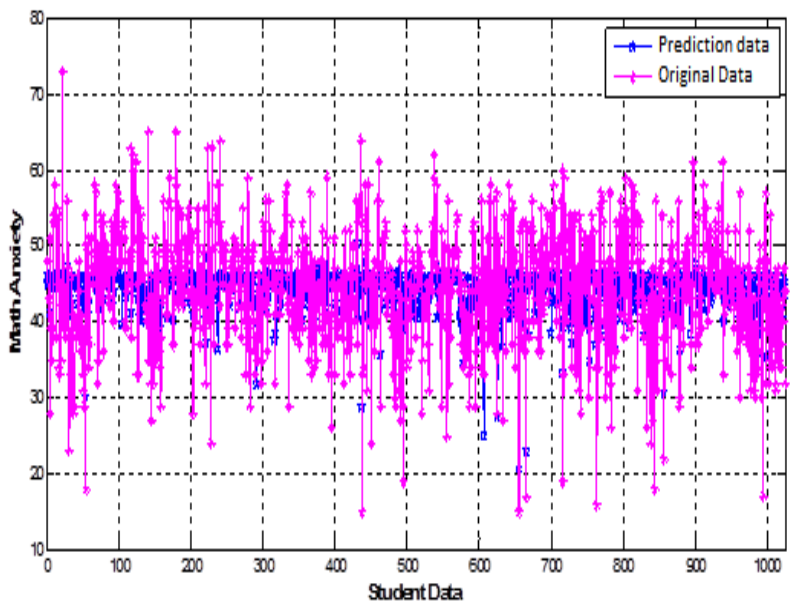

Figure 3 The original and predictive anxiety data using model 1

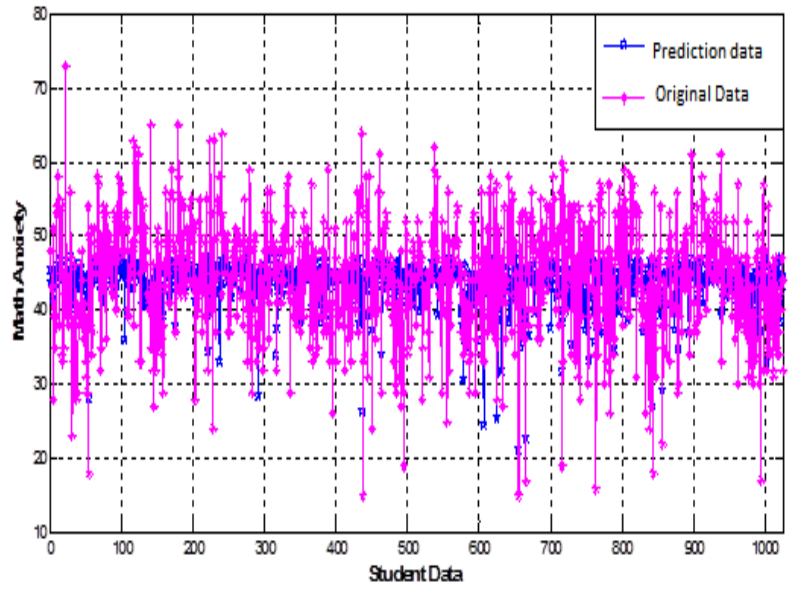

Figure 4 The original and predictive anxiety data using model 2 


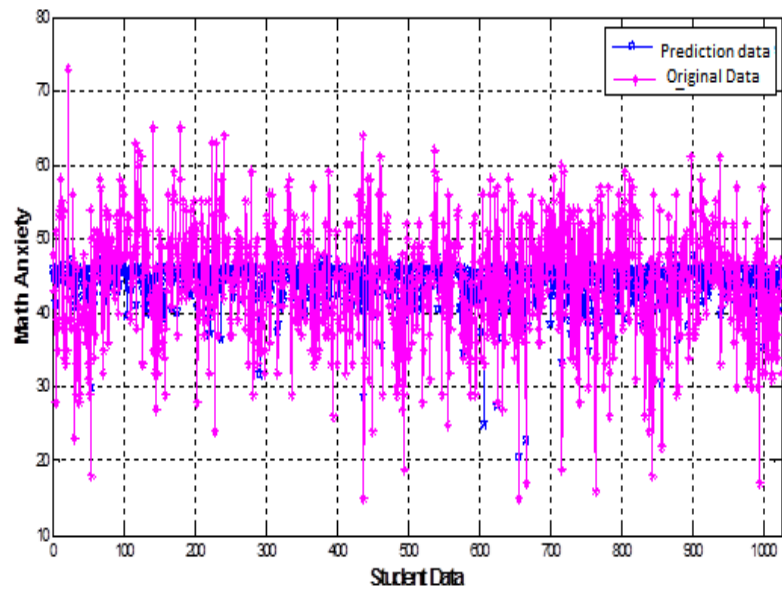

Figure 5 The original and predictive anxiety data using a regression model

\section{CONCLUSION}

This study concludes that the fuzzy model developed using Wang's method until the third step is better than the model developed using the final step. In addition, the advantage of the fuzzy model is that it can control uncertainty better than the regression model can.

\section{REFERENCES}

[1] M. H. Ashcraft, Math anxiety: Personal, educational, and cognitive consequences, Curr. Dir. Psychol. Sci., vol. 11, no. 5, 2002, doi: 10.1111/1467-8721.00196.

[2] M. H. Ashcraft , A. M. Moore, Mathematics anxiety and the affective drop in performance, J. Psychoeduc. Assess., vol. 27, no. 3, 2009, doi: $10.1177 / 0734282908330580$.

[3] G. Ramirez, H. Chang, E. A. Maloney, S. C. Levine, S. L. Beilock, On the relationship between math anxiety and math achievement in early elementary school: The role of problem-solving strategies, J. Exp. Child Psychol., vol. 141, 2016, doi: 10.1016/j.jecp.2015.07.014.

[4] T. Woodard, No Title, Inquiry, vol. 9, no. 1, pp. 15, 2004, [Online]. Available: https://eric.ed.gov/?id=EJ876845.

[5] E. Zakaria, N. M. Nordin, The effects of mathematics anxiety on matriculation students as related to motivation and achievement, Eurasia J. Math. Sci. Technol. Educ., vol. 4, no. 1, 2008, doi: 10.12973/ejmste/75303.

[6] M. Alves, C. S. Rodrigues, A. M. A. C. Rocha, and C. Coutinho, Self-efficacy, mathematics' anxiety, and perceived importance: An empirical study with Portuguese engineering students, Eur. J. Eng.
Educ., vol. 41, no. 1, 2016, doi: 10.1080/03043797.2015.1095159.

[7] J. K. Jasmina Pekić, Ilija Milovanović, Selfefficacy in mathematics and math anxiety in high school: gender differences, 2017, [Online]. Available:

https://www.researchgate.net/publication/3205596 89_SELF-

EFFICACY_IN_MATHEMATICS_AND_MATH _ANXIETY_IN_HIGH_SCHOOL_GENDER_DIF FERENCES.

[8] M. Chaman, R. Callingham, Relationship between mathematics anxiety and attitude towards mathematics among indian students, Mathematics Education Research Group of Australasia. 2013.

[9] A. Akin, I. N. Kurbanoglu, The relationships between math anxiety, math attitudes, and selfefficacy: A structural equation model," Stud. Psychol. (Bratisl)., vol. 53, no. 3, 2011.

[10] S. R. Spaniol, Students' mathematics self-efficacy, anxiety, and course level at a community college," 2017.

[11] G. S. Kushwaha, S. Kumar, Role of the fuzzy system in psychological research, Eur. J. Psychol., vol. 5, no. 2, 2009, doi: 10.5964/ejop.v5i2.271.

[12] Subanar, A. M. Abadi, Contribution of fuzzy systems for time series analysis, in The 6th SEAMS-UGM Conference 2011, 2011, pp. 1-11, [Online]. Available: http://staffnew.uny.ac.id/upload/132128276/penelit ian/full+paper+seam+subanar_revisi.pdf.

[13] H. P. Susanto, D. Daeka, Prediksi besar gempa di sekitar pulau jawa menggunakan pemodelan fuzzy, Beta J. Tadris Mat., vol. 8, no. 1, pp. 79-85, 2015, [Online].

Available: https://jurnalbeta.ac.id/index.php/betaJTM/article/v iew/26.

[14] H. R. G. M. Mazaheri, H. M. Nehi, Application of fuzzy system in psychological tests: optimize the number of questions for WHOQOL-BREF, Int. J. Psychol., vol. 9, no. 5, 2015, [Online]. Available: http://www.ijpb.ir/article_55590.html.

[15] A. Mustafa, A.-H. A. Hashim, O. Khalifa, S. A. Hamed, Adaptive Emotional Personality Model based on Fuzzy Logic Interpretation of Five-Factor Theory, Signal Process. An Int. Journal, vol. 2, no. 4, 2014, [Online]. Available: https://www.researchgate.net/publication/4184599 4_Adaptive_Emotional_Personality_Model_based _on_Fuzzy_Logic_Interpretation_of_Five_Factor_ Theory. 
[16] L.-X. Wang, A course in fuzzy a course in fuzzy systems and control," Design, 1997.

[17] A. M. Abadi, S. S. Saleh, Widodo, S. Saleh, A new method for generating fuzzy rules from training data and its application to forecasting inflation rate and interest rate of bank indonesia certificate, J. Quant. Methods, vol. 5, no. 2, 2009.

[18] A. M. Abadi, A new fuzzy modeling for predicting air temperature in Yogyakarta, in the IceMATH, 2011, pp. $\mathrm{xx}-\mathrm{xx}, \quad$ [Online]. Available: http://staffnew.uny.ac.id/upload/132128276/penelit ian/paper+agus+ICeMATH2011.pdf.

[19] Lewis, Industrial and business forecasting methods: a practical guide to exponential smoothing and curve fitting, Butterworth Sci., no. June 1981, 198 